\section{Edgard Roquette-Pinto: Antropologia brasiliana}

Por Renan Freitas Pinto

Doutor em Sociologia pela Pontifícia Universidade Católica de São Paulo. Professor do Instituto de Ciências Humanas e Letras da Universidade Federal do Amazonas (erfreitaspinto@vivax.com.br)

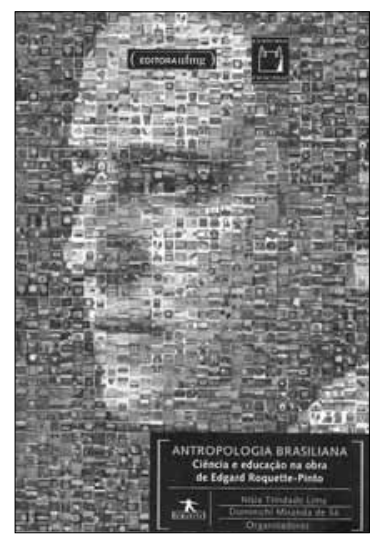

LIMA, Nísia Trindade; SÁ, Dominichi Miranda de (Orgs.).

Antropologia brasiliana: ciência e educação na obra de Edgard Roquette-Pinto. Belo Horizonte: Editora UFMG; Rio de Janeiro: Editora Fiocruz, 2008. 327 p. ISBN: 978-857041-724-4 (Editora UFMG) 1978-85-7541-163-6 (Editora Fiocruz).

O primeiro aspecto a ser destacado desta obra coletiva sobre o pensamento e a vida de Edgard Roquette-Pinto é que ela vem preencher uma ausência que se fazia sentir em termos de um balanço de sua presença entre aqueles autores que marcaram, com suas obras e ideias, as direções para trilharmos os caminhos que nos levam à formação do Brasil moderno. Uma coletânea, portanto, que sob vários aspectos estava faltando, especialmente neste momento em que já dispomos de vários trabalhos dessa natureza, ou seja, de coletâneas destinadas a abordar, de diferentes perspectivas, autores que se tornaram, eles próprios, esses caminhos inevitáveis, essas pistas necessárias para nos aproximarmos de outros pensadores brasileiros.

Obra coletiva dedicada a elucidar os diferentes significados do personagem Roquette-Pinto em termos de suas contribuições, em diferentes campos de conhecimento, para a construção, seja do pensamento social brasileiro, seja de nossa história das ideias e de nossa história das ciências, construindo simultaneamente uma das mais originais interpretações da formação do povo e da nação brasileira.
O livro está organizado em quatro partes, iniciando a primeira com um manuscrito até então inédito do próprio Roquette-Pinto, resultante de uma palestra por ele proferida a convite do Itamaraty e que aqui tem a oportunidade privilegiada para sua publicação na medida em que, para as organizadoras da obra, pode ser lido como uma reflexão sobre seu próprio "lugar e papel na sociedade". Os demais artigos dedicados ao autor, compondo o conjunto de textos que pretendem se concentrar, conforme a indicação do subtítulo do livro, nos temas da ciência e da educação na obra de Roquette-Pinto, na verdade, nos brindam com um espectro bem mais abrangente e mais diferenciado de sua obra, de suas ideias e de sua presença como intelectual e homem de ação.

É basicamente sobre o alcance e a amplitude desta obra realizada com a colaboração de cerca de 15 autores, oferecendo-nos uma visão de conjunto adequadamente articulada de modo a indicar a presença de Edgard Roquette-Pinto como um dos mais instigantes e originais pesquisadores em busca de novos modos de desvendar o Brasil e os 'brasilianos', assunto a que nos propomos dedicar nossa atenção daqui em diante.

Em primeiro lugar, essa obra recria coletivamente um personagem de primeira linha. E o recria entrelaçando informações e pontos de vista que, em busca de fatos inéditos, de anotações essenciais, de pistas esclarecedoras, algumas vezes se repetem sem que, entretanto, isso represente qualquer prejuízo, bem ao contrário, ajude o leitor a reconhecer nesse entrelaçado de rememorações, urdido por vários narradores, a força, a presença e a carga de originalidade do personagem Edgard Roquette-Pinto.

É, ainda, uma obra que, por ser coletiva e logo reconhecida por seu amplo espectro temático em torno da contribuição antropológica de Roquette-Pinto, nos oferece a liberdade de nela ingressar escolhendo nosso próprio ponto de partida, nossa própria sequência de leitura.

Uma das ideias que acompanham RoquettePinto ao longo de toda sua extensa produção e de suas diferentes atuações nas instituições com que se envolveu,

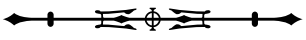


e certamente também em suas ações de homem público, é o reconhecimento do papel crescente da ciência como fundamento necessário para as mudanças que precisam ocorrer principalmente no campo da educação.

Trata-se, aqui, não simplesmente de ser um representante do positivismo e do racionalismo, que possuíam na ciência um de seus princípios básicos, mas de discordar e de se contrapor a algumas correntes e ideias da ciência vigentes no seu tempo. Um dos principais marcos desse seu pensamento em dissonância com as crenças e posicionamentos da ciência é aquele relacionado com as noções de raça, miscigenação e eugenia que RoquettePinto contestava usando o argumento de que não se tratava de aceitar o fatalismo da existência de raças inferiores e degeneradas e da miscigenação como uma deformação. A própria eugenia que é proposta e defendida por RoquettePinto possui um sentido de melhoria da saúde do povo brasileiro pela atenção, sobretudo, aos seus quadros de miséria e pobreza e, em especial, de uma atenção redobrada à educação, porque é precisamente aí que residiria não apenas a causa de todos os nossos principais males, mas a possibilidade de superação.

Em vários autores presentes na coletânea há indicações de que, já em seus escritos bem iniciais, é a educação o fundamento que cimenta todo o pensamento de RoquettePinto e que orienta suas ações ao longo da vida e obra.

Certamente, um tema reconhecidamente controverso é o do lugar que as ideias positivistas ocuparam no Brasil para a constituição do campo das ciências e para a definição do cientista como um dos atores principais no jogo da reorganização da sociedade brasileira. E graças à riqueza de detalhes que a obra nos propicia em relação à presença do positivismo, é possível indicar os principais movimentos e situações como, por exemplo, sua conexão com o movimento abolicionista e a campanha pela instauração da República. Devem ser lembrados, ainda, o credo da ciência como alavanca da civilização, a construção de modelos de organização social voltados para o bem-estar comum. Outro discurso emblemático é o da defesa da nacionalidade, tendo como ponto de apoio a ciência, e que se contrapunha ao que se reconhecia como o nacionalismo romântico.

Cabe mencionar também as referências ao positivismo como responsável pela difusão de ideias, progressistas, como a da necessidade do cultivo de uma antropologia anti-racista, da busca de um compromisso com a coisa pública fundado na probidade administrativa, na atenção para com a garantia de condições dignas de trabalho operário, o empenho em se garantir a toda a população as condições básicas de saúde e da educação como o fator capaz de tornar os indivíduos aptos a vencer a pobreza e a ignorância.

Um dos artigos se concentra na tarefa de examinar o lugar de "Rondônia", seu livro mais divulgado e mais conhecido por leitores especialistas e pelo público mais amplo interessado nesse relato sobre o Brasil indígena (Roquette-Pinto,1975). O próprio autor reconhece nesse livro seu empreendimento científico mais elaborado e que trouxe uma contribuição que não se resume à etnografia, mas que se torna um dos textos essenciais para compreendermos o Brasil indígena e aspectos do sertão distante que necessita fazer parte da nacionalidade.

A obra é dedicada a Cândido Mariano da Silva Rondon, "figura mítica do Brasil republicano", distinguindose, principalmente, o sentido que Rondon atribuía à questão indígena, ou seja, como questão de responsabilidade do Estado brasileiro traduzida na ideia guia de tutelar e proteger o índio.

Quanto ao próprio Roquette-Pinto, que participou da Comissão Rondon como observador médico e, sobretudo, interessado em coletar peças da cultura material indígena, fornece-nos informações essenciais relacionadas com a concepção e construção da obra. Primeiramente, indica que o livro é, em grande parte, transcrição de seu caderno de campo, o que fica claro pelo fato de que vários parágrafos se iniciam com referência a mês e dia em que as anotações foram feitas. Além desse aspecto de caderno de campo, Roquette-Pinto indica um outro elemento que faz com que o livro funcione como um catálogo das coleções obtidas durante a expedição e que seriam destinadas a enriquecer o acervo do Museu Nacional, no Rio de 
Janeiro. Cabe anotar que, entre esses materiais, estão os instrumentos musicais, de arte plumária e de cerâmica.

O livro reproduz partituras de música indígena resultantes de transcrições realizadas por Astolfo Tavares a partir de gravações fonográficas e que, posteriormente, receberiam arranjos de Heitor Villa-Lobos, que também as aproveitaria para futuras composições.

Outro aspecto apontado pelos autores é que RoquettePinto empreende, no primeiro capítulo, um balanço de registros sobre a área abrangida pela exposição, com um interesse especial nas referências aos Nambikwára e Paresi. Para Roquette-Pinto, o principal acontecimento de toda a expedição está descrito no sexto capítulo, ou seja, para ele, o tão esperado primeiro contato com os Nambikwára. Nos capítulos seguintes, o leitor vai se defrontar com anotações detalhadas sobre essa população indígena que possuía uma significação especial para o jovem etnógrafo.

Não podemos deixar de observar que os autores apontam também para a contribuição da expedição a um conhecimento mais detalhado da geografia do território em questão. Na verdade, essa contribuição ocupa parte significativa da obra.

Além da etnografia indígena, a obra trata também da etnografia do sertanejo, numa clara inspiração nos "Sertões" de Euclides da Cunha, e, nesse sentido, ele vai abordar os seringueiros como a expressão humana mais forte desse outro sertão que é a região amazônica.

A perspectiva modernista está presente no livro "Rondônia", como em sua convicção da necessidade de nos voltarmos para esse país rural e atrasado, para isso, concebendo a missão da difusão do rádio e do cinema, assunto que poderia ser melhor examinado, segundo os autores, por meio da correspondência mantida entre Mário de Andrade e Roquette-Pinto.

Roquette-Pinto é conhecido e reconhecido como o idealizador do rádio como instrumento de educação capaz de chegar aos 'brasilianos' mais isolados geograficamente, e também aos que não sabem ler, mas que podem aprender e se desenvolver culturalmente. Está cada vez mais claro para nós, hoje, que, além de seu pioneirismo e de tudo quanto realizou em benefício da criação do rádio e do cinema educativo, na realidade, encontrou muitos obstáculos para levar adiante seu projeto de transformar o país atrasado, analfabeto e doente em uma nação tal como é apresentada em muitos dos programas de rádio e em boa parte da produção fílmica do Instituto Nacional de Cinema Educativo (INCE). Como anotam os autores, os filmes terminam por projetar uma imagem romântica e otimista, exaltando o perfil de vultos nacionais e de uma natureza pródiga, como são exemplos os filmes sobre a vitória-régia e sobre peixes do Rio de Janeiro. Como sugerem vários trechos do artigo sobre o INCE, esses filmes conduzem seus espectadores a empreenderem, à semelhança dos naturalistas e viajantes do século XIX, uma viagem ao Brasil, a ciência realizando aí sua tarefa de decifração e revelação de um povo e de um país extraordinários.

\section{REFERÊNCIA}

ROQUETTE-PINTO, Edgard. Rondônia. São Paulo: Editora Nacional; Brasília: INL, 1975. 
